\title{
The Application of Problem Based Learning in Undergraduate Nursing Education: A Strategy for Curriculum Reform
}

\author{
Tan Kan Ku', Michael Ha ${ }^{2}$ \\ ${ }^{1}$ Victoria University Institute of Technology (VUIT), St. Albans Campus, Melbourne, Australia \\ ${ }^{2}$ MSc Financial Mathematics Programme, Xi'an Jiaotong-Liverpool University, Suzhou, China \\ Email: tankanku@gmail.com, Tan.Ku@vu.edu.au, Michael.Ha@xjtlu.edu.cn
}

Received 23 June 2016; accepted 27 June 2016; published 30 June 2016

\section{Abstract}

Background: Problem based learning (PBL) is an innovative way of delivering instruction in which problems are used as the basis of learning. Problem based learning was developed in the 1960s by Harold Barrows at McMaster University Medical School in Canada. Since then, PBL had been implemented as a teaching method in other reputable education institutions internationally, including nursing education. Curriculum reform is proposed through PBL in conjunction with patient simulation in undergraduate nursing education. The first author, Tan Kan Ku, PhD Candidate, MHS (Transcultural Mental Health-by Research) worked as a Registered Nurse for more than two decades internationally in England, New Zealand, Saudi Arabia and Australia, where she worked as a Case Manager in Community Mental Health Rehabilitation Program. Since 2001, she focused on nurse education and research into the stigma of mental illness from a cross-cultural perspective. Currently, she teaches Mental Health, Cultural Diversity and Research in the Diploma of Nursing course at Victoria University in Melbourne, Australia, while completing her PhD thesis for examination at Charisma University. The second author, Dr. Michael Ha, FSA, MAAA, CFA, CPA (Australia) FRM, PRM, LLM, is the Founding Director of the MSc Financial Mathematics programme at Xian Jiaotong-Liverpool University. He was previously Vice President of Strategic Business Initiatives Units at ING Life Insurance in its Taiwan operation. Ninety percent of his students are enrolled in the Financial Mathematics programme. They learn not only mathematics and statistics theories but also their applications in the Finance and Investment areas, especially Portfolio Construction and Financial Risk Management. Creating a real-world Finance work environment in university lecture-halls embracing theories and practice, Dr. Ha strongly believes the PBL method can be employed in the Financial Mathematics training agenda so students can be better-prepared for work. Students are no longer instructed-learners but active thinkers and problem-solvers. Conclusion: Educators in fields such as Medical, Nursing, Engineering, Financial Mathematics, Accounting, Computing, etc., need to be prepared to change their teaching philosophy from didactic to problem solving for PBL to be implemented. Constructive alignment is recommended for curriculum reform. 


\section{Keywords}

\section{Problem Based Learning, Critical Thinking, Patient Simulation, Nurse Education, Constructivism}

\section{Introduction}

This paper provides a description of PBL as an active learning method, using a problematic stimulus for student nurses to develop and acquire knowledge. Further discussion includes the first author's personal perspective as the Unit Co-ordinator in the delivery of the Unit "Monitoring and Implementing Nursing Care for Consumers with Mental Health Condition” (HLTEN510B). Application of PBL increased student nurses' critical-thinking, practised patient simulation in a safe environment had helped them to achieve their learning objectives. Problem based learning was an effective learning approach when learning outcomes were specified clearly to prepare students to attend mental health clinical placement ( 80 hrs) after having 36 hours of theory and passing a written test of 2 hours' duration. Problem based learning as a strategy was proven to be effective as evidenced from positive student performance appraisals received from public and private health facilities in Melbourne, Australia.

\section{Historical Overview of Problem Based Learning}

The problem based learning idea originated from Case Western Reserve University in the mid-1950s (Baker, 2000 [1]; O’Kelly et al., 2000 [2] and Savery and Duffy, 1996 [3]). It was formally developed by Harold Barrows, a Professor at McMaster University in the 1960s in response to medical students' discontentment with lectures delivered in classroom. Furthermore, Harold Barrows noticed that many medical graduates were unable to apply classroom teaching to clinical practice (http://www.pbli.org/faculty/hsb.htm) [4]. By the $20^{\text {th }}$ Century, almost 150 medical schools internationally had adopted problem based learning in their curricula (Spencer \& Jordon, 1999) [5].

Traditional medical and nursing curricula were based on conservative method in delivering lectures to the learners, who in turns, were expected to use memory based learning to pass written examination, and went on to be qualified doctors and nurses. The lack of application of critical thinking and problem solving skills from the students' perspective prompted Harold Barrows to formally developed PBL as a pedagogical approach. PBL uses case study, vignette format and scenario, and problems as the starting point for obtaining learning objectives. This approach enables adult learners to challenge others' point of view and use evidence to support their own views.

\section{Process of Problem Based Learning}

Problem based learning emphasises on the content to be learned and the learning process (Barrows, 1983 [6]; Barrows, 1995 [7]). PBL comprises several components:

a) The presenting problem acts as a "trigger" for the session,

b) The student participants discuss the problem in small group of 5 - 6 within a given time frame,

c) The educator facilitates the learning process occurring through the PBL sessions,

d) Lectures (such as power point presentations) are reduced and form part of the curriculum,

e) Self-directed learning is recommended which is a crucial part of the process.

\section{Constructing the Problem Based Learning Session}

Nursing academics in the $21^{\text {st }}$ Century in Australia have suggested that PBL is a strategy typically used with small groups attending a series of sessions (Rogal \& Snider, 2008) [8]. Schmidt’s (1983; 1993) [9] [10] model is constructed as a pyramid with seven steps jumping from 1 to 7 . Figure 1 shows the 7-step sequences which are described as follows:

1) Clarify and agree on definitions and unclear terms and concepts. An example of this is exposure to the problem. The nurse educator identifies the problem stimulus, for instance, a Chinese student with a history of depression presents at Emergency Department (Triage). Students are given the opportunity to ask questions or obtain more information from the educator to clarify concepts. (Questions can be "what brought her to Triage?” 
or “did she go to Triage alone?”, “did she try to kill herself?” or “why was she depressed?”).

2) Define the problem(s); agree with phenomena which require clarification. When the information is clear, students "jump" to Step 2 and identify the problem (s).

3) Analyse the problem through brain storming. Students can progress to Step 3 to analyse the problem based on prior learned knowledge and applying the knowledge to current situation. (Prior knowledge is student's acknowledgment of performing a suicidal risk assessment for all patients with a history of depression).

4) Formulate hypotheses after agreeing on possible explanations about the problem leading to analysis of the presenting information. This is accomplished through acknowledgment of what the students know or do not know.

5) Generate and prioritize learning objectives (e.g., how to assess suicide risk; what questions to ask the patient to find out if she is suicidal).

6) Research to meet the learning objectives. Students utilise the time allocated between the sessions to achieve the learning objectives through self-directed study.

7) Synthesise and apply newly acquired data to the problem. Students discuss their findings when the group reconvenes and the educator facilitates the group discussion through the process of solving the problem.

\section{Problem Based Learning-A Nurse Educator's Personal}

The change of Australian nurse education system from hospital training into tertiary sector began in the 1980s, a positive factor which boosted the credential of nurses to be recognised as academic professional. However, there had been ongoing debate about the readiness of Graduate nurses to practise competently after graduation with a Diploma or a Bachelor degree (Heath et al., 2002) [11]. One common criticism of the university system is the limited amount of time allocated to student nurses in clinical setting. On full time basis, Diploma of Nursing (Dip.) students (18 months course) have five weeks and the Bachelor degree (BA) candidates (three years course) have 12 weeks of clinical placement respectively. Nurses are the most numerous professional group, in comparison with other health workers (doctors, psychologists, occupational therapists, social workers, physical therapists), spend the largest amount of time with patients. Thus, it is important that student nurses be equipped with critical thinking, analytical, communication and interpersonal skills to practise competently and efficiently. Subsequently after graduation, nurses will have considerable opportunity to influence patients' attitudes towards their treatment regime, rehabilitation and recovery phase through the medium of interpersonal interaction between the nurse and the patient.

The first author teaches subjects in the second phase of the first and second year of the Diploma of Nursing course at Victoria University in Melbourne, Australia. It had been noted that these student nurses lacked critical analytical skills, particularly in their first clinical placement (Aged Care). Lack of critical thinking skills was partly due to a big proportion of teaching delivery was via power point presentation through traditional teaching method. Major use of power point (PPT) and handouts in teaching are considered as demotivating factors in

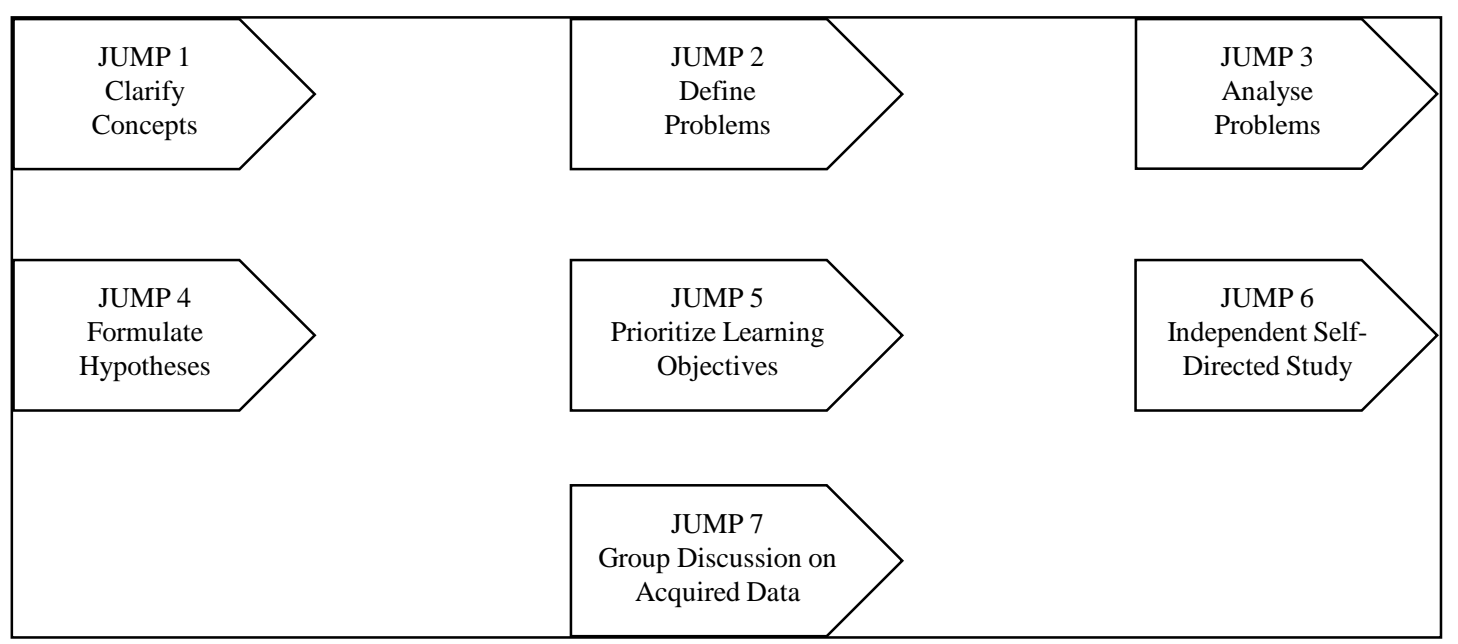

Figure 1. The 7-step model of problem based learning. 
student's learning (Fry et al., 2009) [12]. Hence, since 2012, she decided to apply PBL in the delivery of the Unit HLTEN510B as a preparatory step before students attending clinical placement.

The critical thinking skills required of a graduate nurse are stipulated in the Victoria University (VU) Agenda and Blueprint for Curriculum Reform (2012, P. 19 Section 3.2.3) [13]. It is a requirement from the Australian Nursing and Midwifery Council (ANMC) that the graduates must be able to demonstrate critical thinking in the conduct of the enrolled nurse (ANMC, October 2002) [14]. It is also expected that the Diploma graduates to have critical thinking skills as per the learning outcomes for Australian Quality Framework (AQF) level 5. Problem based learning (PBL) provides a right environment for students to utilise critical thinking.

\subsection{Curriculum Reform}

Reform is necessary to meet the objectives of the VU curriculum reform framework and the ANMC requirements. This curriculum reform process is moving away from teacher focus to student focus. The PBL and Patient Simulation (PS) approaches seek to utilise a constructivist mechanism in teaching and learning. The constructive alignment method is highly recommended by Biggs and Tang (2007) [15] and is aimed at improving student nurses’ critical thinking skill before clinical placement.

\subsection{Critical Thinking}

Critical thinking skill is the fundamental tool required of a nurse besides integrating theory and clinical procedures. In the course of graduating as a nurse, the student through applying critical thinking, specific nursing knowledge, techniques and procedures are enacted through the medium of interpersonal interaction between the nurse and the patient (Ku \& Minas, 2010) [16]. This is particularly important in aged care/mental health clinical placements when students encounter patients with various psychological/emotional problems, and physical disability (the elderly ones in particular). These complex conditions may contribute to difficulty in establishing a nursepatient relationship, as the patient may not be able to verbally express his/her needs due to hearing and sight loss, depression, or dementia. There are ways to prepare students to use critical thinking to be confident to face 'the real world' when they go on clinical placement.

The nurse educator should provide an environment which promotes students to think, to do literature review, to watch a video, to write case history, to practise patient interviewing skills, practical procedures, sharing individual thoughts with colleagues, and a forum for open discussion. This can be done individually or in group of 4 or 5 as self directed learning (SDL). Encourage inter-cultural assimilation among students (in choosing group membership) is another way for students to learn from one another in a class of different ethnic groups. For example, after the first session on Mental Health, students were given Case Study with two scenarios as SDL. They were supposed to present answers to the 10 questions in the third session. This is encouraging individual/group work, building a team spirit, which they can carry on at clinical placement. A reflective journal also helps in critical thinking skills when students can identify their strength and weakness. Concept mapping (CM) is another method suggested by Burrell (2014) [17] in curriculum design as it allows students to analyse, interpret, integrate data by linking with health care concept.

\subsection{Reflection}

Reflection can be used in classroom and in clinical placement by students to evaluate their own performance. After each face-to-face classroom teaching session, students are encouraged to write a self report reflecting how much he/she has understood the theory being taught. In clinical placement, students are asked to keep a journal reflecting: their feeling as clinicians, their prospect of team work, their strengths and weaknesses and attitudes towards nursing as a profession.

\subsection{Problem Based Learning (PBL) in Delivery of HLTEN510B}

Problem based learning provides a framework for students to work in group for the exchange of ideas, opportunity to effective communication/interpersonal skills, team work, and management skills. Problem based learning also helps in establishing social and cultural interaction among students of diverse age groups, ethnic and social economic backgrounds. Furthermore, Kong et al. (2014) [18] proposed PBL, as a strategy for promoting critical thinking, have more advantages than using traditional teaching/learning method which is the teacher teaches 
from PPT and book, and students write down notes from white board or power point.

When applying PBL in nursing, case scenarios in vignette format are presented to the students, who have to collaborate with classmates to present their findings. In this way, they share and construct new knowledge based on previously learned knowledge (Fry et al., 2009) [12]

Problem based learning, combined with constructive alignment, contributes to students' achieving critical thinking and problem solving skills (Yuan et al., 2008) [19]. When confronted with a nursing issue, the students use their theoretical knowledge, to analyse the presenting data and come up with a judgement of the situation, which could be a nursing diagnosis, care plan, contingency plan and prognosis. The judgement could be disputed by others (particularly those who have worked in aged care and mental health as Personal Care Assistant (PCA). As long as the judgement can be justified in certain context, PBL promotes group work. It helps students to appreciate others' opinions, which prepare them to be good citizens, and will be reflected in the nurse-patient relationship. This is because patients may not agree with the nurse's opinion in the caring process. For example, nurses have to ensure diabetic patients' understanding of the impact of monitoring their diet and blood glucose level. PBL can assist nurses in promoting the consumer-partnership paradigm, which is to engage the patient as collaborator in the individualised care planning. The skills obtained from PBL can enable a student or graduate nurse to integrate theory and practice within his/her own knowledge development within any nursing context.

Simulation in nursing education provides students with a safe environment to practise that mimics the real situation. It promotes confidence in decision making when being confronted with a real problem in clinical placement. Simulation manikin is a highly sophisticated computerised hardware program that provides real medical conditions. Practice under this environment will not be harmful to the participants (Murray et al., 2008) [20] as it is carried out in the nursing laboratory. Case scenarios are programmed by the computer and students practise on the manikin. But this cannot be accomplished in learning communication skills, which is pivotal in mental health nursing.

Educators have a professional and ethical responsibility through the provision of an environment of trust, and respect for the students. That is, allow the students to take responsibility for their learning and action under supervision by the educators. An open dialogue is encouraged whereby students can actively engage with other students and the educator. Students must be empowered to speak their mind without any adverse effect. Students' active involvement in a free zone environment allows deeper engagement of cognitive and affective functioning. Hence, students are free to express their cultural, moral and ethical values, with subsequent expression in cultural exchange. This environment promotes group membership within the student cohort and in the workplace when students graduate from the nursing course.

"Simulated exercises can be developed to learn error management and hazardous procedures such as safe blood transfusion practice” (Murray et al., 2008, p. 6) [20]. Students can slowly build up their confidence before their clinical placement. Simulation has gained popularity within nursing education in the last decade (Murray et al., 2008) [20]. However, the one obvious disadvantage is the cost involved associated with purchase of software and maintenance cost.

\section{Patient Simulation Session in Delivery of HLTEN510B-An Example}

Prior to 2014, simulation related to mental health nursing was done via watching videos of real case scenarios to prepare students with a safe environment to practise skills on placement. This is because mental health cannot be taught in a nursing laboratory, unlike practical procedures. Since 2014, the Culture Respect Encompassing Simulation Training (CREST) program was integrated to assist with simulation in mental health nursing. Several case scenarios of patients suffering from mental illness are carefully selected to include patients of different health beliefs from a transcultural perspective. The simulation session includes assessing students' interviewing skills, care planning and interaction skills with patients who have been diagnosed with mood disorder, anxiety disorder, schizophrenia, personality disorder, obsessive-compulsive disorder and dementia.

On the day of simulation training, a patient (who had undergone training to behave as a patient with mental illness, in this case, depression) was pre-arranged to meet with the teacher prior to the patient entering the class to be interviewed by student volunteers. The session guidelines were explained in handouts (student notes). The teacher/educator followed teacher's notes for the session.

Four students (two Australians and two Indians) volunteered to interview the patient independently with evidence based scenario. After data gathering from the patient, students were observed on how they utilised communication/interpersonal skills to engage with the patient. Students presented the data and their judgement to the 
class through interviewing skills to find out more about the patient. Questioning was used to determine why certain strategies were used while others were opted out towards a case of depression. The patient was initially not communicative and spoke in mono tone. Other students acted as observers to give feedback. Teacher acted as observer and assistant to student volunteer who were struck with questions.

A debrief session was used to evaluate the session, for example, discussion centred on why the student volunteers had used certain action, judgement and attitude towards the simulated patient. The simulated patient (a middle aged Chinese lady) also provided feedback. She commented it was the best session she had ever been as a patient. She praised on students demonstrating respect towards her as "a patient with 'odd' behaviour", and disclosed that she had indeed suffered from cancer, although at the time, she had recovered from the illness. Feedback from students (volunteers and observers) agreed that the session had helped to increase their confidence in interviewing skills, data gathering and interpersonal interaction, which they could transfer in real life situations (Alinier, Hunt \& Gordon, 2004) [21].

\section{Constructive Alignment}

Constructive alignment is student focused and is delivered to meet the learning outcomes. Constructive alignment is described by Biggs and Tang (2007) [15] when students construct their cognitive knowledge based on what they already know (in classroom, laboratory and simulation), so when students enter a health facility, they have pre-existing knowledge of the type of patients they are expected to nurse. This knowledge is increased step by step in a gradual fashion in order to build up the required knowledge. The teacher acts as a facilitator to bring student to assimilate new learning. This is known as the zone of proximal development, defined by Vygotsky (1978) [22] as what the students have developed, the potential of what students could develop through the assistance of teachers or fellow classmates.

Constructivism is a framework that encourages students to utilize their ability to synthesize, and through reflection, they build new learning into pre existing knowledge. Alignment is achieved when activities arranged by the teacher meet the intended learning outcomes (Biggs \& Tang, 2007) [15]. It is paramount that teachers write clear and precise intended learning outcomes (Schmidt, et al., 1993) [23] reflecting the level and standard for which they are written. The activities that the students perform must align appropriately to achieve the intended learning outcomes. It is the teacher's responsibility to provide a suitable environment for performing these activities. PBL supports this environment.

Assessment of intended learning outcomes demands that the students provide evidence to indicate the outcomes have been achieved. This can be in the form of providing a portfolio of assessment tasks, such as documentation in a reflective journal, power point presentation or video recording.

\section{Feedback from Health Facilities}

Since PBL was integrated in delivering training to Diploma students, they have gained confidence and were able to pass the Case Study scenarios and written tests before attending clinical placement. Excellent performance appraisal was received from health agencies (public/private mental health facilities) where students attended for their clinical placement. A small number was given jobs as PCA and were guaranteed employment in mental health facility as Division 2 nurses before they qualified with a Diploma of Nursing.

\section{Advantages of Problem Based Learning}

Problem based learning is student-centred learning which encourages students to take charge of their own education, that is, to be dynamic learners who can integrate course related knowledge and apply in clinical setting. Vittrup and Davey (2010) [24] revealed that PBL not only benefited the under graduates, but the post graduate nurses in enhancing critical thinking. This is in the context of allowing graduate nurses to integrate theoretical knowledge into practice. Graduate nurses can use available resource materials given at PBL sessions to understand patients more comprehensively through doing further research, and obtaining information with their peers to share knowledge about the patient and made a comprehensive assessment on the patient.PBL works well in small groups where the teacher can go round the classroom facilitating students' learning. Problem based learning enables teacher and students' interaction in an informal environment, which is less intimidating for free expression of thoughts and ideas (Lubaway, 2003 [25]; Wood, 2003 [26]). PBL is a bridge connecting theories and 
real-world applications in a more-friendly and familiar environment allowing students to acquire practical skills. In contrast to PBL, traditional teaching methods help students to acquire textbook theories only.

\section{Disadvantages of Problem Based Learning}

Despite the advantages of applying PBL, Vittrup and Davey (2010) [24] have acknowledged one fundamental challenge faced by the educator, which is the extra time devoted in devising authentic scenarios, preparing activities, guiding students until they feel confident in their problem solving skills. To enable activities to be conducted smoothly, adequate room availability for group activities need to be considered in implementing PBL (Gwee, 2009) [27]. There is also the cost and time involved in training educators (on full time basis) to facilitate PBL process. Cost is involved in training simulated patient is another factor to consider when contemplating PBL. Stress is also a factor that may be experienced by both the faculty and students during the orientation process in implementing PBL.

\section{Conclusion}

This paper discusses the need for curriculum reform to meet the required attributes as per Victoria University curriculum blue print and the ANMC standard. It highlights problem based learning as an effective strategy to increase critical thinking skills for undergraduate nurses. Problem based learning in conjunction with patient simulation as a framework for curriculum reform is proposed. Educators need to be prepared to change their philosophy of teaching from didactic to problem solving for PBL to be successfully implemented.

\section{Authors' Contributions}

The first author prepared the first draft of the paper and the second author reviewed and edited the paper. Both authors have approved the final version of the manuscript.

\section{Acknowledgements}

The authors would like to thank Victoria University Institute of Technology and Xian Jiaotong-Liverpool University for supporting and sponsoring the publication of this paper.

\section{References}

[1] Baker, C.M. (2000) Problem Based Learning for Nursing: Integrating Lessons from other Disciplines with Nursing Experiences. Journal of Professional Nursing, 16, 258-266. http://dx.doi.org/10.1053/jpnu.2000.9461

[2] O’Kelly, J., Monahan, R., Gibson, J.P. and Brown, S. (2000) Enhancing Skills Transfer through Problem-Based Learning. Department of Computer Science, Technical Report Series, National University of Ireland Maynooth.

[3] Savey, J.R. and Duffy, T.M. (1996) Problem-Based Learning: An Instructional Model and Its Constructivist Framework. In: Wilson, B., Ed., Constructivist Learning Environment: Case Studies in Instructional Design, N.J. Educational Technology Publications, Englewood Cliff, 135-148.

[4] Barrows, H.S. (2016) Problem-Based Instruction (PBI).

[5] Spencer, J. and Jordon, R.L. (1999) Learner Centred Approaches in Medical Education. BMJ, 123, 534-536. http://dx.doi.org/10.1136/bmj.318.7193.1280

[6] Barrows, H.S. (1983) Problem-Based, Self-Directed Learning. JAMA, 250, 3077-3080. http://dx.doi.org/10.1001/jama.1983.03340220045031

[7] Barrows, H.S. (1995) How to Design a Problem-Based Curriculum for Preclinical Years. Springer Publishing, New York.

[8] Rogal, S.M.M. and Snider, P.D. (2008) The Application of Problem Based Learning Methods to Atypical Contexts. Nursing Education in Practice, 8, 213-219. http://dx.doi.org/10.1016/j.nepr.2007.09.001

[9] Schmidt, H.G. (1993) Foundations of Problem-Based Learning-Some Explanatory Notes. Medical Education, 27, 422-432. http://dx.doi.org/10.1111/j.1365-2923.1993.tb00296.x

[10] Schmidt, H.G. (1983) Problem-Based Learning: Rationale and Description. Medical Education, 17, 11-16. http://dx.doi.org/10.1111/j.1365-2923.1983.tb01086.x

[11] Heath, P., Duncan, P., Lowe, E., Marci, S. and Ramsay, J. (2002) National Review of Nursing Education 2002: Our 
Duty of Care. Australian Department of Education, Science and Training, Canberra.

[12] Fry, H., Ketteridge, S. and Marshall, S. (2009) Teaching and Learning Higher Education—Enhance Academic Practice. 3rd Edition, Taylor \& Francis, New York.

[13] Victoria University (2012) VU Agenda and Curriculum Blueprint: Capabilities for the Future. The University, Melbourne.

[14] Australian Nursing and Midwifery Council (2002) National Competency Standards for the Registered Nurse.

[15] Biggs, J. and Tang, C. (2007) Teaching for Quality Learning at University. 3rd Edition, McGraw Hill, UK.

[16] Ku, T.K. and Minas, I.H. (2010) Development of the Nursing Relationship Scale: A Measure of Interpersonal Approaches in Nursing Care. International Journal of Mental Health System. http://dx.doi.org/10.1186/1752-4458-4-12

[17] Burrell, L.A. (2014) Integrating Critical Thinking Strategies into Nursing Curricula. Teaching and Learning in Nursing, 9, 53-58. http://dx.doi.org/10.1016/j.teln.2013.12.005

[18] Kong, L., Qin, B., Zhou, Y.-Q., Mou, S.-Y. and Gao, H.-M. (2014) The Effectiveness of Problem-Based Learning on Development of Nursing Students' Critical Thinking: A Systematic Review and Meta-Analysis. International Journal of Nursing Studies, 51, 458-469. http://dx.doi.org/10.1016/j.ijnurstu.2013.06.009

[19] Yuan, H., Williams, B.A. and Fan, L.A. (2008) Systematic Review of Selected Evidence on Developing Nursing Students' Critical Thinking through Problem-Based Learning. Nurse Education Today, 28, 657-663. http://dx.doi.org/10.1016/j.nedt.2007.12.006

[20] Murray, C., Grant, M.J., Howarth, M.L. and Leigh, J. (2008) The Use of Simulation as a Teaching and Learning Approach to Support Practice Learning. Nurse Education in Practice, 8, 5-8. http://dx.doi.org/10.1016/j.nepr.2007.08.001

[21] Alinier, G., Hunt, W.B. and Gordon, R. (2004) Determining the Value of Simulation in Nurse Education: Study Design and Initial Results. Nurse Education in Practice, 4, 200-207. http://dx.doi.org/10.1016/S1471-5953(03)00066-0

[22] Vygotsky, L.S. (1978) Mind in Society-The Development of Higher Psychological Processes. Cole, M., John-Steiner, V., Scribner, S. and Souberman, E., Eds., Harvard University Press, Cambridge.

[23] Schmidt, H.G., Van der Srend, A., Moust, J.H., Kokx, I. and Boon, L. (1993) Influences of Tutors' Subject-Matter Expertise on Student Effort and Achievement in Problem-Based Learning. Academic Medicine, 68, 784-791. http://dx.doi.org/10.1097/00001888-199310000-00018

[24] Vittrup, A.C. and Davey, A. (2010) Problem-Based Learning_-Bringing Everything Together”-Strategy for Graduate Nurse Programs. Nurse Education in Practice, 10, 88-95. http://dx.doi.org/10.1016/j.nepr.2009.03.019

[25] Lubaway, W.C. (2003) Evaluating Teaching Using the Best Practices Model. The American Journal of Pharmaceutical Education, 67, 87. http://dx.doi.org/10.5688/aj670387

[26] Wood, D.F. (2003) ABC of Learning and Teaching in Medicine: Problem-Based Learning. British Medical Journal, 326, 8. http://dx.doi.org/10.1136/bmj.326.7384.328

[27] Gwee, M.C.E. (2009) Problem-Based Learning: A Strategic Learning System Design for the Education of Healthcare Professionals in the 21st Century. Kaohsiung Journal of Medical Sciences, 25, 231-239. http://dx.doi.org/10.1016/S1607-551X(09)70067-1

\section{Submit or recommend next manuscript to SCIRP and we will provide best service for you:}

Accepting pre-submission inquiries through Email, Facebook, LinkedIn, Twitter, etc.

A wide selection of journals (inclusive of 9 subjects, more than 200 journals)

Providing 24-hour high-quality service

User-friendly online submission system

Fair and swift peer-review system

Efficient typesetting and proofreading procedure

Display of the result of downloads and visits, as well as the number of cited articles

Maximum dissemination of your research work

Submit your manuscript at: http://papersubmission.scirp.org/

Or contact jbm@scirp.org 